\title{
Library Services to the Graduate Community: The University of Michigan
}

This paper discusses the unique problems and special needs of graduate students and how one library, dedicated to serving graduate students, attempts to provide specialized programs to meet their needs. The setting of goals, the establishment of priorities, and staff involvement in the planning and development of new programs are reviewed.

0 WING TO THE GREAT INFLUX of undergraduate students in the 1950s and 1960 s, academic institutions, and hence libraries, directed their major efforts toward the development of programs and facilities for undergraduates. Graduate students, despite their increasing numbers (more than two and a half times as many nationwide in the years between 1960 and 1972), ${ }^{1}$ were, if not forgotten, largely ignored. Concurrent with the emphasis on undergraduates there was a tremendous increase in all types of publishing coupled with large infusions of federal money to library book budgets. Together the emphasis on undergraduate programs and the intensive development of book collections occupied and preoccupied librarians to such an extent that there was almost precluded the possibility of directing any special attention to the needs and problems

Connie R. Dunlap is university librarian, Duke University, Durham, North Carolina. This article is based on a talk given at the ACRL University Libraries Section program on library services to the graduate community at the ALA Conference in San Francisco, July 1, 1975. At that time the author held the post as deputy associate director, University Library, University of Michigan, Ann Arbor. of graduate students. It was not until the late 1960 s that librarians really began to take notice of the increasingly large graduate student population which, by that time, was a complex mix of students from a wide variety of backgrounds. Today affirmative action and equal opportunity programs are opening graduate education to students who frequently have special needs and special problems that require service on an individualized basis. A still different kind of need is presented by the "older" students, especially those in fields in which knowledge and training quickly become obsolete, who are returning to the campus in greater and greater numbers for brief refresher courses. Each group of students makes very different demands on the library.

In addition to a shift in the mix of students, many significant developments have taken place in higher education. Methods of teaching and course content have changed considerably, and research is becoming more diversified and more specialized. As a consequence, graduate students are making less use of prescribed reading lists and course reserves and greater use of a broad range of materials. The application of the interdisciplinary approach to nearly all fields 
of study and the growth of new combinations of subject matter within fields have tended to promote more independent study and research. The interdisciplinary approach has caused the creation of a vast array of specialized reference tools to provide in-depth access to materials in related disciplines, but it is also creating a massive void for which suitable reference works are not yet available. Reference librarians are thus required to become increasingly imaginative and creative in ferreting out needed information. The use of a wide variety of technological aids, from the computer to videotape, has opened new areas for research and has provided new techniques for supplementing classroom teaching. Their use has promoted the creation, in many institutions, of an entirely new concept of library service which provides the students with specially equipped carrels or viewing rooms for using slides, movies, videotapes, or closed-circuit television.

It is becoming increasingly apparent that providing a large book collection is only one element of good library service. Research libraries are extremely complex organizations; and unless service programs designed to teach students the effective and efficient use of a large library are fully developed, their rich resources will lie largely untapped except to a knowledgable few. We cannot continue to justify the expenditure of millions of dollars each year to build collections which are only minimally used. New ways must be developed to permit and encourage greater exploitation of the collections. Given present economic conditions, there seems little likelihood that budgets for staff will be augmented to any significant degree in the foreseeable future so the cost of such programs may have to be funded, to some extent at least, at the expense of the book budget. The idea of sacrificing a small part of the book budget for service programs will become less abhorrent as national plans for resource sharing and cooperative collection development reach a more advanced state and as specialized programs for graduate students are more highly developed and have fully proved their worth.

\section{Graduate Students' NeEdS}

In studying for the doctoral degree, graduate students are attempting to gain in-depth knowledge of a specialized field and to prepare for a career in which research is a basic element. To achieve these goals, a thorough understanding of the organization and intricacies of a large library and the acquisition of research skills are absolutely essential. A recent survey by the Dissertation Review Committee in the Graduate School at the University of Michigan revealed that faculty, Ph.D. candidates, and Ph.D. alumni felt that the five most important objectives of the dissertation were to acquire broad research skills, to organize and communicate research findings, to develop the capability of making future contributions to knowledge, to identify important problems, and to develop high-level problem-solving skills. According to the survey, the respondents' judgments about the importance of dissertation objectives are related in part to the academic division in which they operate. By and large, the life and physical scientists were most oriented to high-level problem-solving, contributing thereby to the advancement of knowledge. To a lesser extent, the social scientists were concerned about essentially the same things. Ph.D.'s in humanities and education, on the other hand, had a greater interest in more generalized research skills than in high-level problem-solving skills and placed greater emphasis on communication to the public and to students in the classroom. ${ }^{2}$ To achieve these objectives, graduate students must be given a thorough indoctrination into the effective methods of using library 
resources if they are to develop fully their capacity to pursue research independently.

\section{ONE Institution's ResPonse}

In an institution such as The University of Michigan, which grants Ph.D. degrees in over 100 fields and master's degrees in more than 150 and which has over 15,000 graduate students who are required to work through the maze of one of the largest research libraries in the country, the need for specialized programs is obvious and overwhelming. These programs necessarily take a wide variety of forms according to the community of scholars served. A number of libraries at Michigan have special programs for graduate students.

For example, the automated data bases in MEDLINE, the independent interlibrary loan network established by the National Library of Medicine, make available to clientele of the Medical Center Library the broad range of medical and related scientific literature. Under development at the Medical Center is a massive media program to coordinate the use of all video and audio materials for the medical community. Computerized carrels will be an important component of this new service.

The Engineering Library has developed two special programs to instruct students, faculty, and others about the resources and services of that library. Only about one-third of the individuals taking advantage of these programs are engineers, the other two-thirds being library science students, faculty, or representatives of local industry. One is a slide presentation illustrating the use of the catalogs, basic indexes, and the union list and delineating the kinds of services available. The slide presentations are narrated by staff, rather than being recorded on tape, to permit interaction between staff and viewers. In this way the students can stop the presentation to ask questions or to request fur- ther explanation. The other program is divided into three sets: indexes and abstracts, patents and standards, and government documents and technical reports. In this latter program, it was decided against using an audiovisual approach because the information is more detailed and more difficult to grasp. Instead, liberal use is made of brochures showing examples of types of materials and giving explanations of how to use the tools in the field. Both programs have been highly successful. ${ }^{3}$ Other divisional libraries, besides engineering and medicine, have also developed special programs according to the needs of the students they serve.

The Graduate Library at Michigan, which houses the main research collection, serves primarily, but by no means exclusively, the graduate students and faculty in the more than thirty academic departments in the social sciences and humanities. Students in these disciplines rely most heavily on the library for their research and require the broadest range of scholarly materials and the greatest diversity of special services. If such students wander aimlessly about the library, testing and probing with only marginal success, the quality of their work is diminished and the time necessary to complete it is lengthened.

In order to meet the widely varying needs of a large graduate student population and a research-oriented faculty, as well as to serve as the primary research library on campus and as a resource library for the entire state, it has been necessary for the Graduate Library to develop or expand a broad range of services. These include the traditional services of information, reference, interlibrary loan, and microforms, among others, to which a number of new services have been added including a serials service, a publishing program, and bibliographic instruction.

Since the control and servicing of periodicals and serials had long been a ma- 
jor weakness, high priority was given to improving service in this area. Included are a noncirculating periodical collection comprising the bound volumes of about 400 of the most heavily used titles and an adjacent current serials service, which incorporates an improved method of controlling unbound serial publications and an expanded serials reference service. An index room containing the periodical and newspaper indexes and the major abstracting services was established in close proximity to both the current serials service and the public catalog.

A completely different kind of service, designed to provide students with a wide variety of specialized information needs, has been a publishing program. The most significant of the publications in the program is the Graduate Library Guide Series, which ultimately will provide each discipline or special subarea with critically annotated bibliographies of the major research tools in the field.

Another type of program, and the one which has had the greatest impact on the training of graduate students and which will have the most far-reaching ramifications for the future, is bibliographic instruction. This program has dealt the most directly with the specialized needs of graduate students and gives them extensive training in research methodology and an in-depth introduction to research materials. Term-long courses are tailored to the specific needs of advanced graduate students in a given subfield, and the techniques learned can be applied to related disciplines and to any other research library. In addition to providing them with subjectspecific information, students are taught how to dispel the mysteries of a large library. These courses, taught in the library by librarians, are a direct scholarly service to the academic programs and have resulted in a major extension of the library's contribution to the educa- tional process. It is also this service which most closely parallels the mission of the university-the advancement and organized transmission of learning. When fully developed, this program will have a major impact on teaching and research and also on the status and stature of librarians in the academic community.

\section{Implementing Change}

Making significant changes in service patterns is sometimes very difficult, especially when those changes require substantial alteration of attitudes and habits. The Graduate Library at The University of Michigan has been fortunate because two major building projects over the last ten years have made change an accepted way of life. It has been possible to take advantage of the natural upheaval and resulting physical alterations of a building under construction to shift direction and to introduce a new concept of service with relatively little additional stress. Many of the staff, stimulated by the visual show of progress that the construction of a new building made, were eager to extend that progress to an expansion and improvement of the total range of services offered. Each departmental unit within the Graduate Library was asked to review its operations and to set both shortand long-range goals and priorities. These were correlated and melded with the broader goals of the Graduate $\mathrm{Li}$ brary and with the mission of the university library as a whole.

In the establishment of new service patterns, the primary goals were to develop ways of reaching as many students as possible on as individualized a basis as limited staff would permit, to make an attempt to minimize the factory or supermarket atmosphere of a large institution, and to develop techniques which would make it possible to respond more quickly to the changing needs of students and to changes in the university 
community. In setting priorities, first rank was given to those services which would complement the university's teaching function and the educational process to the greatest extent and which would have the greatest impact on the training of graduate- students. Traditional services, with major improvements, had to be maintained, leaving at the bottom of the list a myriad of miscellaneous functions that are now being done if and as time permits. Backlogs in such areas have rarely been of serious concern; some of them seem no longer to matter very much. Actually, the backlogs are caused primarily by lack of clerical help and have relatively little to do with the new priorities. In most cases the staff has been so stimulated by the new challenges that twice as much is being accomplished.

Setting goals and establishing priorities are relatively easy, or at least relatively easier, in times of restrictive budgets than finding staff with the time, the energy, and the creative ability to plan, implement, and continue new programs. In order to stimulate staff sufficiently to insure full cooperation and to gain a commitment to any new endeavors, it is vital that they be deeply involved in the planning and decisionmaking processes. Major changes cannot be made without their enthusiastic support, for it is they who will do all of the hard work and they who will be directly responsible for any success a new program achieves.

A major consideration in the setting of priorities and the subsequent assigning of duties, whether to professional or to support staff, was to insure that each individual was given opportunity, through a variety of responsibilities, for maximum personal growth and development. It was intended that over a period of time all professional librarians, for example, would be given broad experience, as their talents and inclinations suggested, in supervision, book selection, instruction, reference, and special services. Giving staff a wide range of experience increases their interest in and commitment to the library. It also produces a staff which is very knowledgable and is flexible enough to make shifts in program emphasis with maximum ease. The fullest and best use of our human resources is one of the most important elements in any library service program, and their proper utilization will become even more vital as budgets continue to decline. In order to take advantage of the many technological changes that will occur over the next decade and to implement innovative and personalized services to graduate students and scholars on a much broader scale than is now possible, every creative and driving force in the staff must be stretched to its fullest potential, for it is only by maximizing these resources that we can hope to shape and control the future.

\section{REFERENCES}

1. U.S. Bureau of the Census, Statistical Abstract of the United States: 1975. (96th ed.; Washington, D.C.: Govt. Print. Off., 1975), p.556.

2. "The Doctoral Dissertation Survey," Rackham Reports 2:6 (Spring 1975). This publication is issued by the Horace H. Rackham School of Graduate Studies, the University of Michigan.

3. From a conversation with Maurita Peterson Holland, Engineering Librarian, University of Michigan Library. 